\title{
Modelling and Simulating Stress Distribution on a Centrifugal Pump Shaft during Backpressure
}

\author{
P. B. Sob \\ DepartmentofMechanical Engineering, Faculty of Engineering and Technology, \\ Vaal University of Technology, Vanderbijlpark 1900, Private Bag X021, South Africa
}

ORCID: 0000-0002-1796-7694

\begin{abstract}
Several centrifugal pump shafts have failed during operation due to backpressure. Several approaches have been used to solve backpressure with limited success since most backpressure parameters during backpressure have not been properly model and simulated. Most developed models and simulation of backpressure are derived without taking into accounts all the major parameters that affect the pump system during operation. This has resulted to models and simulation results that are inefficient in predicting the real stress that acts on the shaft during back pressure. As a result, failure in the pump shaft is poorly predicted during backpressure. In the current study all the majors' parameters and variables that affect centrifugal pump shaft during backpressure are considered in modeling and simulation. In this study, the major parameters during backpressure are computed theoretically for optimal stability during operation. The stress-strain relationship are the major parameters computed during backpressure. The stress depends on the intensity of back pressure induced on the shaft during operation. The intensity of back pressure also depends on the valve control process during operation. Failure of the pump shaft due to backpressure occurs when the stress subjected on the material during backpressure exceed the yield strength of the material.
\end{abstract}

In this study, an Auto desk fusion 360 was used to analyze the relationship between back pressure intensity, stress and strain when the shaft is constrained on the drive end bearing and nondrive end bearing using frictionless constrain at extreme back pressure. The following facts were theoretically revealed after modelling the stress-strain relation and performing the relevant simulation using Auto desk fusion 360. The centrifugal pump shaft shows high failure rate at the keyway slot which at increased back pressure the failure is distributed throughout the shaft spindle and as the back pressure is increased the key slot strain increases. The simulated results revealed that at extreme back pressure, failure on the centrifugal pump shaft originate from the keyway slot where analysis shows this area as a high concentrated stress/strain zone. Different stress/strain distribution where revealed under varying backpressure condition which indicated the different category of shaft failure possibility during backpressure. It was also shown that the stress/strain relationship varying under different backpressure condition and critical elasticity zone were revealed in the study.

Keywords: stress, strain, yield strength, centrifugal pump, and failure

\section{INTRODUCTION}

Centrifugal pumps are mostly used in South Africa in water supply system since they provide efficient and more stable supply of water in both domestic and industrial applications. Centrifugal pump gives kinetic energy from impeller rotation to the fluid. The kinetic energy is converted into pressure energy that induces flow of the fluid [Krisna Eka Kurniawan,2018]. One of the main problems affecting centrifugal pumps is unstable performance, such as large pressure changeability. Most often they are reported to be unstable due to backpressure drop that affect the pump performance. Pumps with high operation efficiency will make an important input in the pump system [American water works association manual m14. 2004] and water supply generation.

However, backpressure effects, destroys the shaft of a centrifugal pump during operation. A shaft is the most vital component used in almost every mechanical system and machines. Out of all power transmission components, shaft is the main component which must be designed carefully for efficient working of centrifugal pumps. Shafts are also used in virtually every piece of rotating machinery to transmit rotary motion and torque from one location to another (Patel, Hiren, Prajapati, Dutt and thakar 2014). Most centrifugal pump shaft fails due to backpressure that is greater than the pressure that the shaft can withstand. However, the shaft is not designed to rotate in the opposite direction and any tensioning in the opposite direction leads to shaft failure due to backpressure during shaft operation.

Further investigation by $\mathbf{J}$ Fail, Anal and Preven shows that, sometimes failures are due to poor estimation of mechanical properties of the shaft. From fundamental principle, a shaft backpressure caused backflow due to hydraulic dynamics. It is a reversal of the normal direction of flow due to a downstream pressure that is greater than the supply pressure. Once the pressure on pipe system drops below the atmospheric pressure, negative pressure is generated which causes backflow, which is having a negative impact on centrifugal pump system and components (American water works. association manual m14, 2004).

Preventative measures to prevent or reduce backflow were considered in most centrifugal pump system. Air gap is one of the methods used, which allows the surrounding atmosphere to enter the piping system, which must be placed in such a way that fumes or other mid-air substances cannot be suck up into the water system. They are very safe and reliable if properly 
installed and maintained. Another method used is to reducedpressure assembly which consist of two loaded self-sufficiently acting check valves [which arrest about $(6.9 \mathrm{kPa})$ in the direction of flow of the check valve, with the outlet side of the check at atmospheric pressure] with a hydraulically operating, mechanically independent pressure-differential relief valve located between the check valves below the first check valve, this system is used to maintain pressure that is lower after the first check than it is at the inlet (American water works association manual $\mathrm{m} 14,2004)$.

Pressure vacuum breaker which uses spring loading to actuate the atmospheric vent only when the line is depressurized. Two gate valves, test cocks and an additional first check are also added. This assembly is designed to be used under constant pressure conditions. Pressure vacuum does not protect against backflow due to backpressure and it is useful in high hazard situations. Some of the system uses vacuum breaker to prevent backflow. The common specific of any vacuum breaker is a device designed to prevent backflow backsiphonage. It consists of a combination of check valve and air- inlet valve that admits atmosphere pressure into the downstream piping during operation. Barometric Loop consists of a continuous unit of supply piping that rises to a height of approximately $10.67 \mathrm{~m}$ above the highest outlet served by the pipe and then returns down to the originating level during operation. Its operation is based on the principle that a column of water at sea level pressure will not rise above $10.33 \mathrm{~m}$. The Barometric Loop may be used to protect against backsiphonage, and it may not be used where backpressure may occur. Barometric loop requires a large amount of space for installation and if modifications are done it may destroy its effectiveness (E.R Tomblin et al. 2013). Most of these methods used to prevent backpressure are inefficient during pump operation.

Backpressure continuously impacts a centrifugal pump shaft during operation and this problem need to be addressed. A method of modeling the stress and strain relation for optimal shaft operation during backpressure has not been investigated. A proper modelling of a centrifugal pump stress and strain on the shaft during backpressure can inform the design of a shaft that can withstand backpressure. The backpressure on the centrifugal pump design can be related to a force acting on the centrifugal pump and the force can also be related to the yield stress of the shaft during backpressure. In modeling these parameters, a better shaft that can withstand the backpressure during pump operation. Therefor the aim of this project is to model and design a centrifugal pump shaft with more enhanced mechanical properties that will withstand backpressure during centrifugal pump operation.

\section{MATERIALS, METHODS AND ANALYSIS}

Theories of failure during back pressure will help us to determine the safe dimensions of a centrifugal pump shaft when it is subjected to combined stresses due to various loads acting on it during back pressure. Theories of failure during back pressure are employed in the design of a shaft due to the unavailability of failure stresses under combined loading conditions. Theories of failure during back pressure will play a key role in establishing the relationship between stresses induced under combined loading conditions and properties obtained from tension test like ultimate tensile strength (Sut) and yield strength (Syt) defined as the maximum principal stress $\left(\sigma_{1}\right) \leq \operatorname{permissiblestress}\left(\sigma_{\text {per }}\right)$ given as

$\sigma_{\text {per }}=\frac{\text { failure stress }}{\text { factor of safety }}=\frac{s_{\mathrm{yt}}}{\mathrm{N}}$ or $\frac{\mathrm{s}_{\mathrm{ut}}}{\mathrm{N}}$

$\sigma_{1} \leq \frac{s_{\mathrm{yt}}}{\mathrm{N}}$ or $\frac{\mathrm{s}_{\mathrm{ut}}}{\mathrm{N}}$

This Theory is suitable for the safe design of centrifugal pump shaft made of brittle materials under all loading conditions, triaxial, biaxial and hydrostatic stress because brittle materials are weak in tension, unsuitable for the safe design of machine components made of ductile materials because ductile materials are weak in shear and This theory can be suitable for the safe design of machine components made of ductile materials under following state of stress conditions (a) Uniaxial state of stress ( $\tau_{\max }=\frac{\sigma_{1}}{2}$ ) (b) Biaxial state of stress when principal stresses are like in nature ( $\tau_{\max }=\frac{\sigma_{1}}{2}$ ) and (c) Under hydrostatic stress condition (shear stress in all the planes is zero). Maximum shear stress induced at a critical point under triaxial combined stress must be greater than the Yield strength in shear under tensile

$\tau_{\text {max }}>s_{\text {ys }}$ or $\frac{s_{\mathrm{yt}}}{\mathrm{N}}$

where $\mathrm{N}$ is the factor of safety. The maximum shear stress induced at a critical $\leq$ Permissible shear stress $\left(\tau_{\text {per }}\right)$ tensile point under triaxial combined stress is given as

Permissible shear stress $=\frac{s_{y s}}{\mathrm{~N}}=\frac{s_{y t}}{2 \mathrm{~N}}$

$\tau_{\max } \leq \frac{s_{y s}}{\mathrm{~N}}$ or $\frac{s_{y t}}{2 \mathrm{~N}}$

The system tri-axial state of stress during operation can be established from equation (5) given as

$\left[\frac{\sigma_{1}-\sigma_{2}}{2}\right],\left[\frac{\sigma_{2}-\sigma_{3}}{2}\right],\left[\frac{\sigma_{3}-\sigma_{1}}{2}\right] \leq \frac{s_{y t}}{2 \mathrm{~N}}$

$\left[\sigma_{1}-\sigma_{2}\right],\left[\sigma_{2}-\sigma_{3}\right],\left[\sigma_{3}-\sigma_{1}\right] \leq \frac{s_{y t}}{\mathrm{~N}}$

The system bi-axial state of stress is given as, $\sigma_{3}=0$ and equation (7) can be given as

$\left[\frac{\sigma_{1}-\sigma_{2}}{2}\right] \leq \frac{s y t}{2 \mathrm{~N}}$

$\sigma_{1}-\sigma_{2} \leq \frac{s_{y t}}{2 \mathrm{~N}}$

\section{ANALYSIS OF DISTORTION ENERGY THEORY DURING FATIGUE}

The models are tested by an Auto desk fusion 360 simulation and the relationship between back pressure intensity, stress and strain on the centrifugal pump shaft are analyzed when the shaft 
International Journal of Engineering Research and Technology. ISSN 0974-3154, Volume 13, Number 10 (2020), pp. 2943-2954

(C) International Research Publication House. https://dx.doi.org/10.37624/IJERT/13.10.2020.2943-2954

is constrained on the drive end bearing and non-drive end bearing using frictionless constrain at extreme operating back pressure. The analysis of shaft stress and strain with an increase in discharge and suction back pressure was analyzed based on the derived models given by equation (1-9). For this analysis, the discharge back pressure was assumed to be equal to suction back pressure and therefore the system pressure increased accordingly. It was observed that, the increase in pressure from low back pressure to extreme back pressure varies from $10 \mathrm{MPa}$ to $100 \mathrm{MPa}$. This process determines the critical relationship of increase in backpressure to pump shaft stress and strain during operation given by Fig. 1

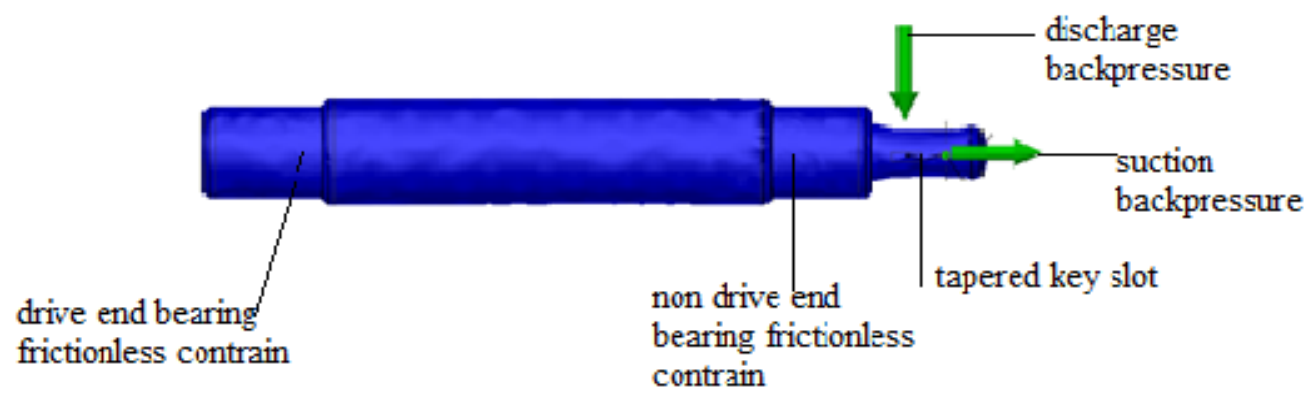

(a)

\begin{tabular}{|cc|}
\hline Material & Mild steel \\
\hline Density & $7.85 \mathrm{E}-06 \mathrm{~kg} / \mathrm{mm}^{-3}$ \\
\hline Young modulus & $210 \mathrm{GPa}$ \\
\hline Poissons ratio & 0.3 \\
\hline Yield strength & $207 \mathrm{MPa}$ \\
\hline Ultimate tensile strength & $345 \mathrm{MPa}$ \\
\hline Thermal conductivity & $0.056 \mathrm{~W} /(\mathrm{mmC})$ \\
\hline Thermal expansion coefficient & $1.285 \mathrm{E}-05 / \mathrm{C}$ \\
\hline Specific heat & $480 \mathrm{~J} /(\mathrm{kg} \mathrm{C})$ \\
\hline
\end{tabular}

(b)

Figure.1 (a) Simulated centrifugal pump shaft and major contact points that impacts stress-strain relationship (b) material properties

\begin{tabular}{|c|c|c|c|c|}
\hline & & failure & & \\
\hline A & B & C & D & $\mathbf{E}$ \\
\hline $\begin{array}{c}\text { Medium } \\
5\end{array}$ & $\begin{array}{c}\text { High } \\
10\end{array}$ & $\begin{array}{c}\text { High } \\
15\end{array}$ & $\begin{array}{c}\text { Extreme } \\
20\end{array}$ & $\begin{array}{c}\text { Extreme } \\
25\end{array}$ \\
\hline $\begin{array}{c}\text { Medium } \\
4\end{array}$ & $\begin{array}{c}\text { Medium } \\
\mathbf{8}\end{array}$ & $\begin{array}{c}\text { High } \\
12\end{array}$ & $\begin{array}{c}\text { High } \\
16\end{array}$ & $\begin{array}{c}\text { Extreme } \\
20\end{array}$ \\
\hline $\begin{array}{c}\text { Low } \\
3\end{array}$ & $\begin{array}{c}\text { Medium } \\
6\end{array}$ & $\begin{array}{c}\text { Medium } \\
9\end{array}$ & $\begin{array}{c}\text { High } \\
12\end{array}$ & $\begin{array}{c}\text { Extreme } \\
15\end{array}$ \\
\hline $\begin{array}{c}\text { Low } \\
2\end{array}$ & $\begin{array}{c}\text { Low } \\
4\end{array}$ & $\begin{array}{c}\text { Medium } \\
6\end{array}$ & $\begin{array}{l}\text { High } \\
8\end{array}$ & $\begin{array}{c}\text { Extreme } \\
10\end{array}$ \\
\hline $\begin{array}{c}\text { Negligible } \\
1\end{array}$ & $\begin{array}{c}\text { Low } \\
2\end{array}$ & $\underset{3}{\text { Medium }}$ & $\begin{array}{l}\text { High } \\
4\end{array}$ & $\begin{array}{c}\text { Extreme } \\
5\end{array}$ \\
\hline
\end{tabular}

Figure 2: Failure rate analysis in a centrifugal pump during backpressure 
The results are computed based on the assumption of linear response of stress during shaft operation. The back pressure in the system was analyzed to find the effect of increase in back pressure to safety factor, Von misses stress and strain of the pump shaft during operation. The shaft is constrained using the frictionless constrains on the non-drive end bearing and drive end bearing. A frictionless constraint prevents the surface deforming in the normal direction relative to the surface. The surface is free to rotate or deform in a tangential direction to the applied frictionless constrain. There is the color description as presented on the results analyzed using Autodesk fusion 360 for proper analysis. The criticality of the shaft failure were indicated using 5 different colours, where blue shows the state of failure that can be negligable,green represent low failure may occur, yellow represent medium failure, orange represent high failure occurrence and red represent extreme failure, therefore failure of pump shaft due to back pressure will be analyzed based on the distribution of different colours in order to find out areas with high rate of failure due to back pressure.

The shaft is made of mild steel material with a physical property that is very strong due to the low amount of carbon used, and the shaft malleable meaning it has high tensile and impact strength. Normally most high carbon steels cracks under varying stress unlike mild steel which bends or deforms easily.
Mild steel has a yield strength of approximately 207MPa with an ultimate strength of $345 \mathrm{MPa}$.

\section{Safety factor analysis}

In this study, the discharge back pressure was assumed to be equal to the suction backpressure during operation and the pressure in the system increased according to the order of low back pressure to extreme back pressure, from $10 \mathrm{MPa}-100 \mathrm{MPa}$ in order to identify the relationship of increase in back pressure to pump shaft stress and strain. The pump shaft must stronger than required to consider its safe design, this is done just in case a pump shaft experience back pressure heavier than expected, which can be considered as overload allow ability. The analysis was done in to find the relationship between an increase in back pressure and safety factor. A factor of safety increases the safety of people and reduces the risk of failure of a pump shaft. A backpressure loading was imposed from discharge pipes which is transmitted to pump impeller located on the shaft end and discharged through suction a pipe which is connected axially to the shaft. The safety factor on the pump shaft was obtained using finite element method because of induced varying back pressure ranged from low to extreme back pressure.

Table1: Revealed the results of back pressure impact on pump shaft safety factor, stress and strain during operation.

\begin{tabular}{|r|r|r|r|}
\hline back pressure(MP) safety factor & stress $(\mathrm{MPa})$ & strain & \\
\hline 10 & 5.608 & 36.9 & $1.74 \mathrm{E}-04$ \\
\hline 20 & 2.804 & 73.83 & $3.49 \mathrm{E}-04$ \\
\hline 30 & 1.869 & 110.7 & $5.23 \mathrm{E}-04$ \\
\hline 40 & 1.402 & 147.7 & $6.68 \mathrm{E}-04$ \\
\hline 50 & 1.122 & 184.6 & $8.72 \mathrm{E}-04$ \\
\hline 60 & 0.9346 & 221.5 & 0.001047 \\
\hline 70 & 0.8011 & 258.4 & 0.001221 \\
\hline 80 & 0.701 & 295.3 & 0.001396 \\
\hline 90 & 0.6231 & 332.2 & 0.00157 \\
\hline 100 & 0.5608 & 369.1 & 0.001744 \\
\hline
\end{tabular}
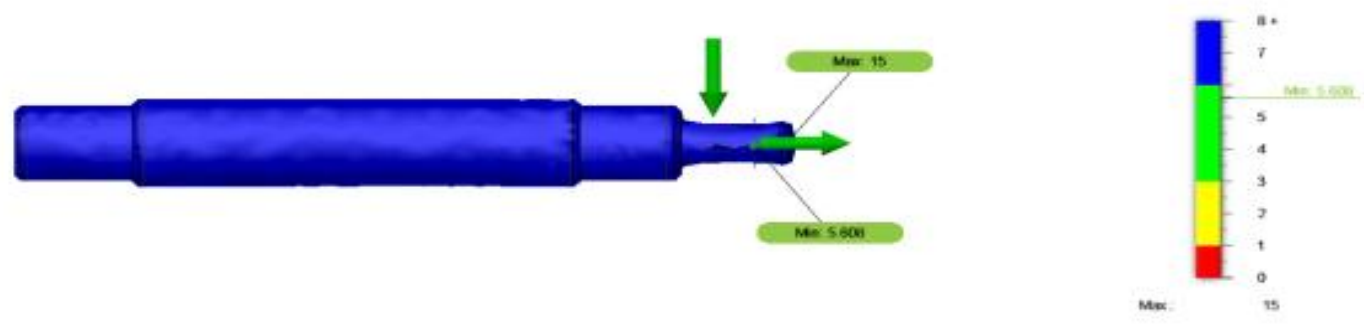

Figure 3: Shaft safety factor at 10MPa during operation 
The result in Fig. 3 revealed the shaft safety factor at $10 \mathrm{MPa}$ back pressure represent maximum failure on the key slot and the failure is represented with a blue colour representing that the shaft is within safe design zone and failure is still at negligible stage, though area of criticality is represented at the key slot with the safety factor of 5.608. From the obtained modeling and simulated results shown in Fig. 3 it is revealed that the shaft operation is safe as further revealed by green color which represent low failure may occur during backpressure. It is also revealed that medium possibility of failure is very low as shown by the yellow color and the chances of critical shaft failure is very low shown by red color. As the safter factors increases during operation from $20 \mathrm{MPa}$ to $100 \mathrm{MPa}$ similar results were revealed as the possibility of the shaft failing during backpressure was very low a shown in Fig. 4 to Fig. 12 . Figure 4 and Fig.5 revealed an increased back pressure from $20 \mathrm{MPa}-30 \mathrm{MPa}$ on the pump shaft during operation and safety factor shows varying failure distribution during simulation process. Observed varying color distribution representing low failure with green color during operation. The shaft spindle where the impeller is mounted changed from blue color to green color during backpressure as shown from Figure 4 to figure 5 showing shaft key slot as failure origin and the more the pressure is increased the green colour distribution on the pump shaft spindle surface area also increases at the magnitude of 2.804-1.869 shown reduction on the pump shaft safety. The failure mode of the shaft during operation start occurring.

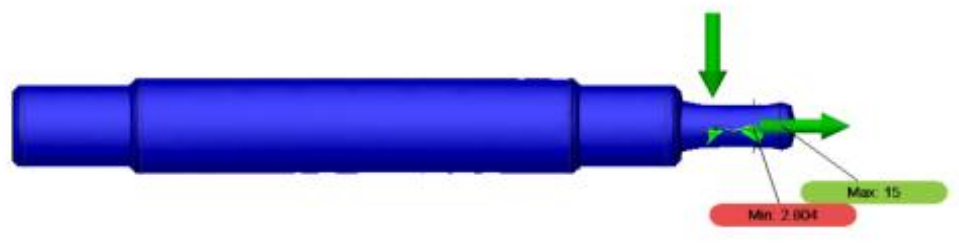

Figure 4. Shaft safety factor at 20MPa during operation

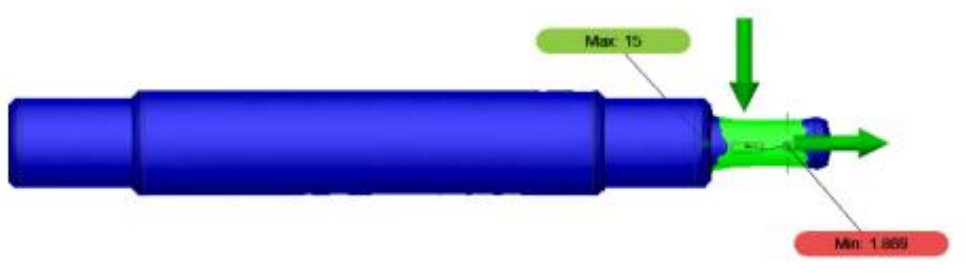

Figure 5. Shaft safety factor at $30 \mathrm{MPa}$ during operation
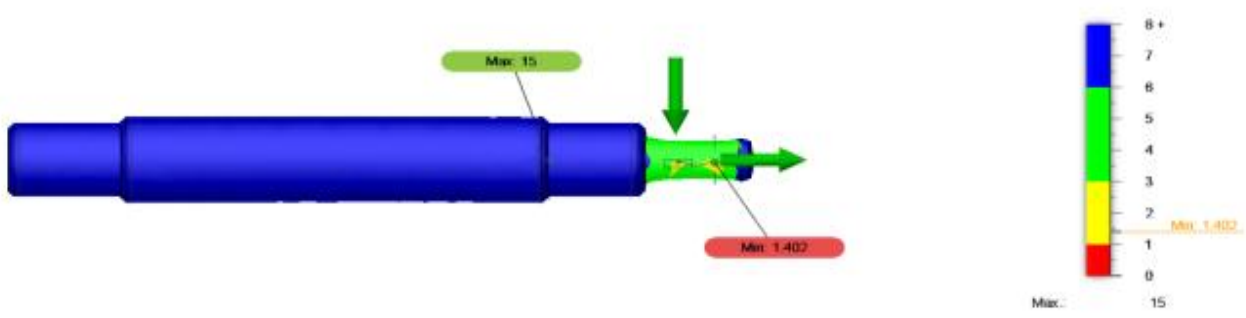

Figure 6. Shaft safety factor at 40MPa during operation 


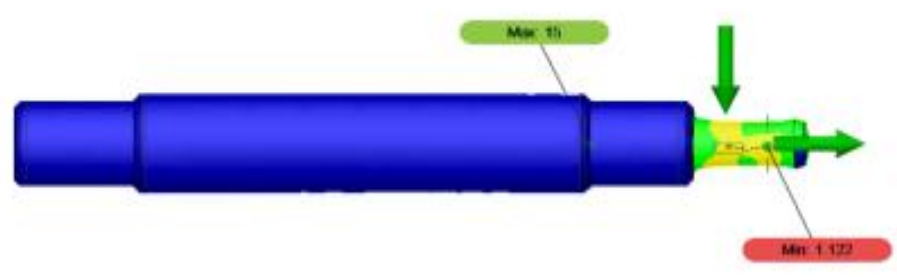

Figure 7. Shaft safety factor at 50MPa during operation
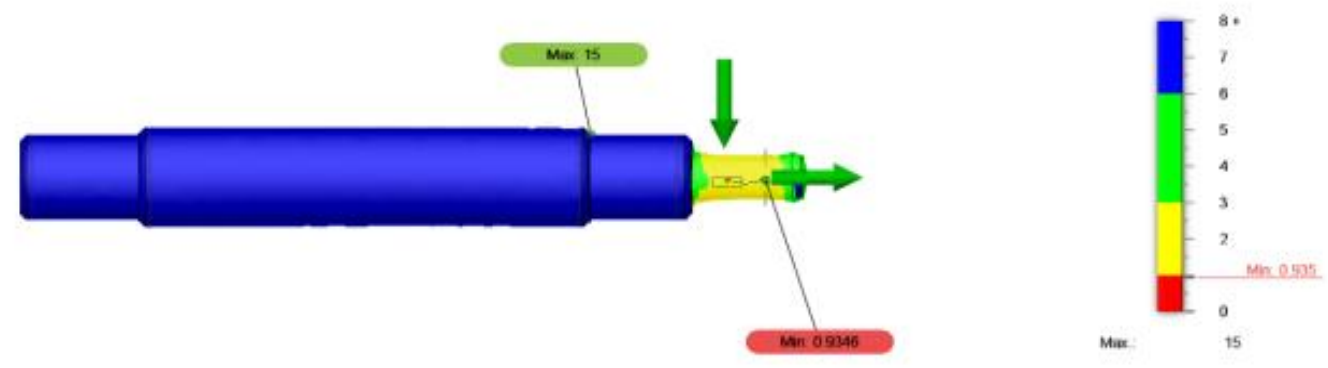

Figure 8. Shaft safety factor at 60MPa during operation
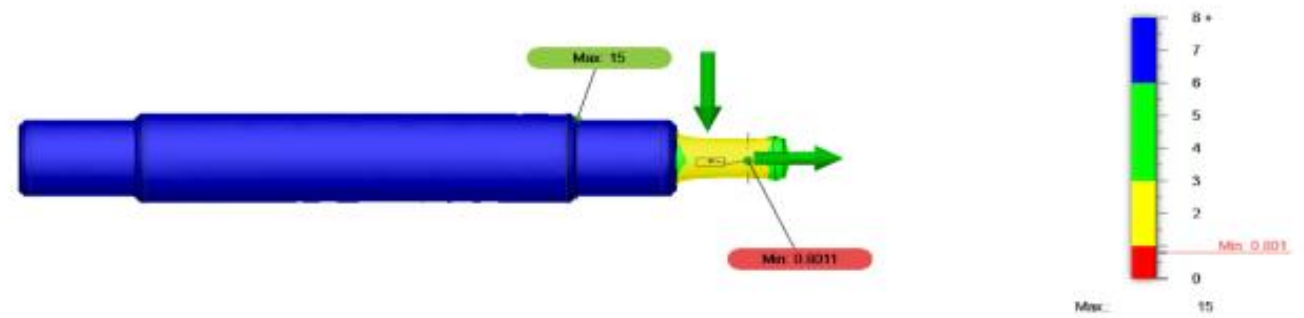

Figure 9. Shaft safety factor at 70MPa during operation
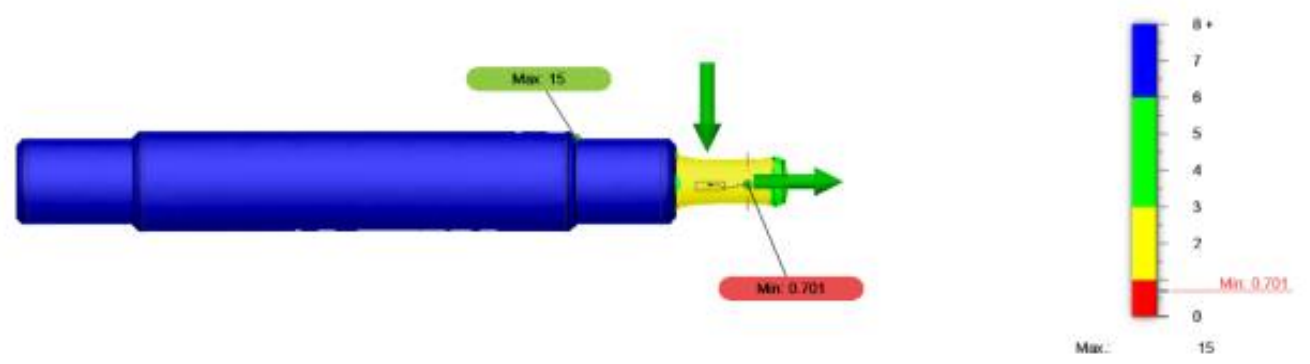

Figure 10. Shaft safety factor at $80 \mathrm{MPa}$ during operation 


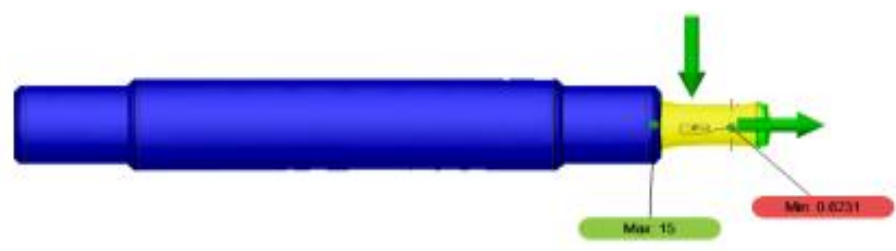

Figure 11. Shaft safety factor at 90MPa during operation
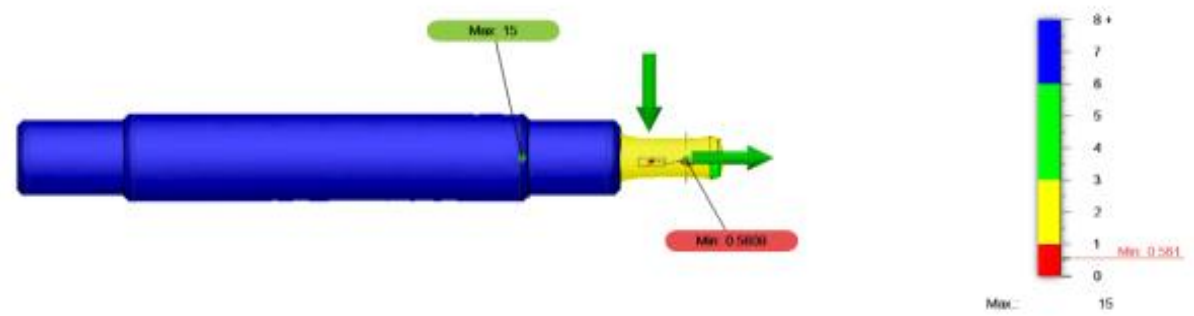

Figure 12. Shaft safety factor at 100MPa during operation

Figure 6 - Fig. 12 revealed back pressure ranging from 40MPa100MP during the pump operation which shows a high failure rate occurring at the pump shaft key slot represented during operation revealed by yellow color with smaller part of the slot experiencing extreme failure represented by red dot. This high failure is distributed originally from the key slot throughout the shaft spindle shown by an increase in distribution of yellow colour and increase in the red dot inside the key slot. From the observed results in this study, it shown that the pump shaft safety factor revealed high possibility of failure originating from the shaft key slot during back pressure and this failure will be distributed throughout the spindle where the impeller is coupled and this failure mode propagate to mechanical failure in the system. The relation between backpressure and safety factor during operation is given by Fig.13.

\section{relationship between back pressure and pump shaft safety factor}

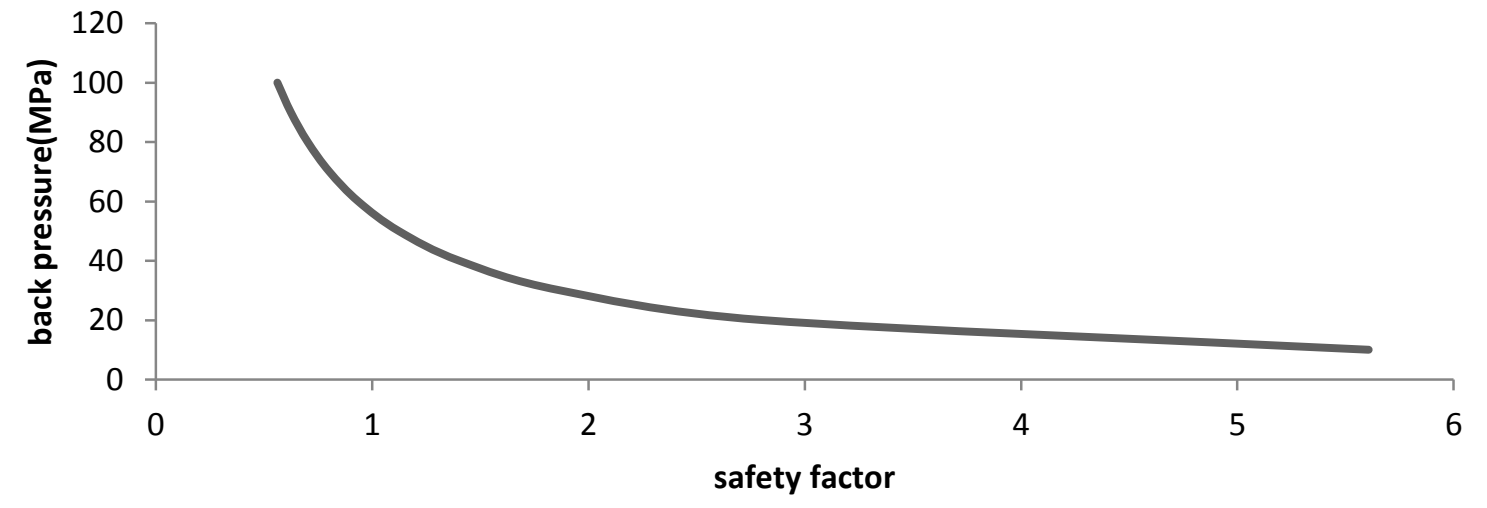

Figure 13 the relationship between backpressure and shaft safety factor during operation 
From Fig.13 the results revealed that as the shaft factor of safety decreases the shaft backpressure increases during operation. The factor of safety and backpressure are inversely related. It should be noted that at very low factor of safety the backpressure in the shaft significantly increases. This is inline with the results discussed in Fig. 3 to Fig. 12. To analyze the stress distribution in the shaft, von misses' stress was used to analyzed the shaft stress distribution at varying back pressure until the yield strength of the mild steel of magnitude $207 \mathrm{MPa}$ is reached and during this process the behavior of the pump shaft was observed at a back pressure higher than then allowable stress in the shaft. Comparison was carried out based on induced varying back pressure and analysis of maximum and minimum Von misses' stresses induced in the pump shaft. Von misses' Stresses in pump shaft caused by back pressure will give a clear idea about whether the pump shaft can withstand extreme back pressure induced on it during operation. If the stress values obtained in this analysis exceed the allowable values, this shows failure of the pump shaft.
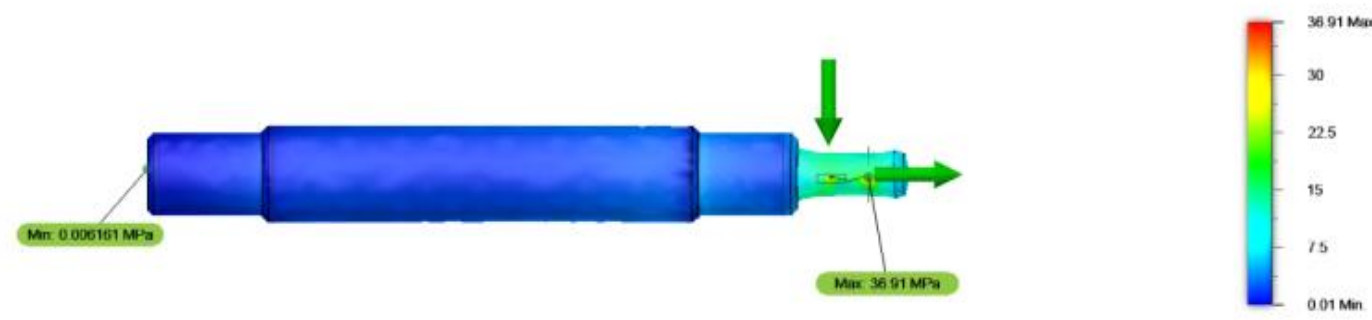

Figure 14. Shaft stress at $10 \mathrm{MPa}$ during operation
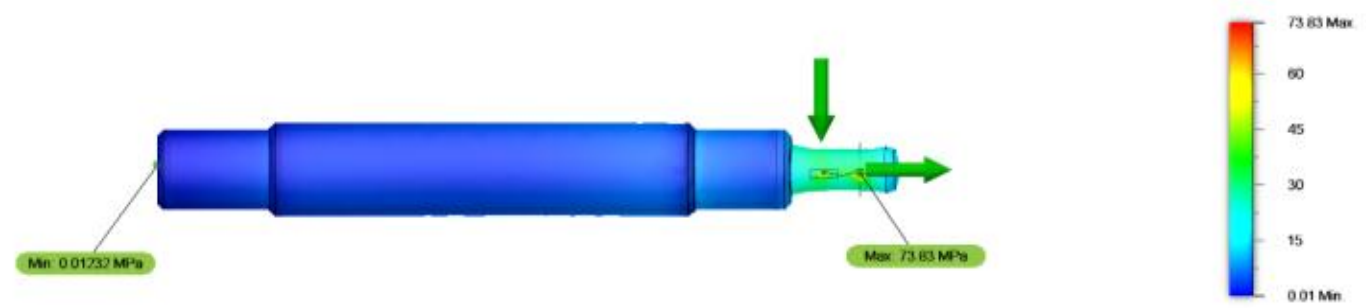

Figure 15. Shaft stress at $20 \mathrm{MPa}$ during operation
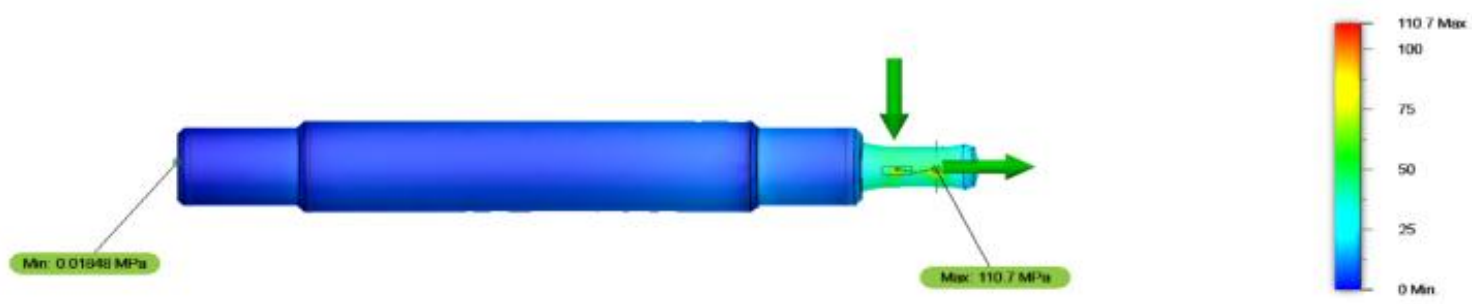

Figure 16. Shaft stress at $30 \mathrm{MPa}$ during operation 


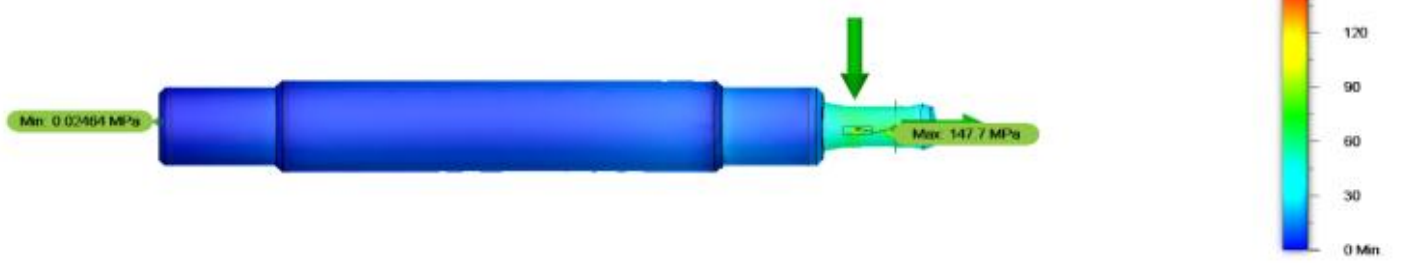

Figure 17. Shaft stress at $40 \mathrm{MPa}$ during operation

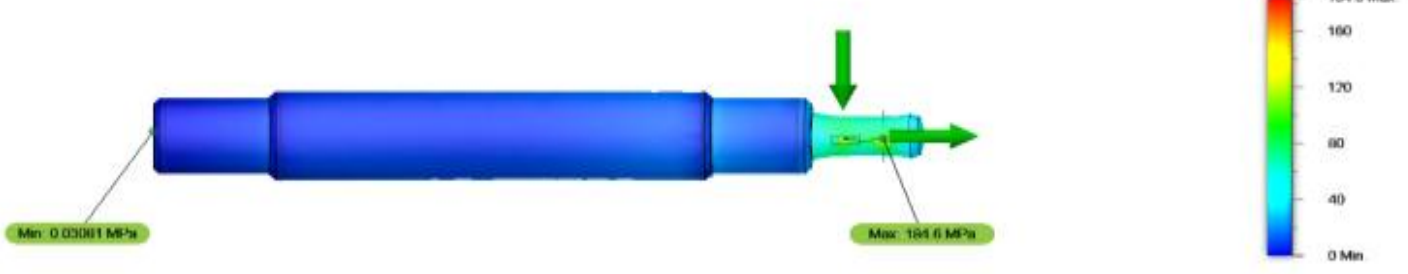

Figure 18. Shaft stress at $50 \mathrm{MPa}$ during operation

Figure 14 to Fig. 18 revealed different shaft stress during backpressure. The results at a stress of $10 \mathrm{MPa}-50 \mathrm{MPa}$ revealed the allowable safe design compliance by indication of maximum Von Misses stress lower than the yield strength at the stress concentrated zone (keyway slot) represented with green color. It also revealed that as the backpressure increases, the stress concentration zone in being impacted and the possibility of shaft failure increases during backpressure. It is also observed that the stress concentrated zone failure increases and some parts of the keyway slot surface area is distributed by yellow colour showing low failure rate at a stress magnitude of
36.9MPa-184. Figure 19 to Fig. 22 revealed the shaft back pressure at stress of $60 \mathrm{MPa}$ to $90 \mathrm{MPa}$ which represent the root of shaft failure due to the shaft Von Misses stress ranging from 221.5MPa-332.2MPa being greater than the yield strength $(207 \mathrm{MPa})$ at the stress concentrated zone. The root of the key slot provided failure origin for the shaft spindle by distributing the yellow color on its surface area and the distribution of failure increase as the back pressure is increased until the failure become more extreme on the other part of the keyway slot represented red color.
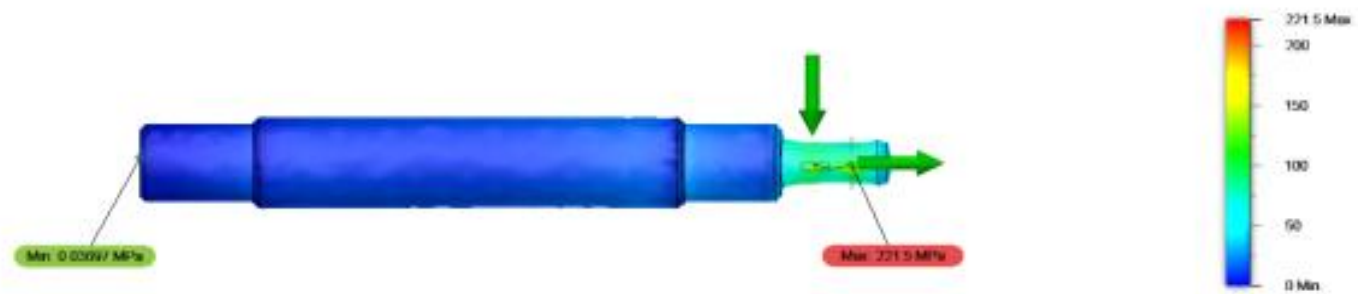

Figure 19. Shaft stress at $60 \mathrm{MPa}$ during operation 

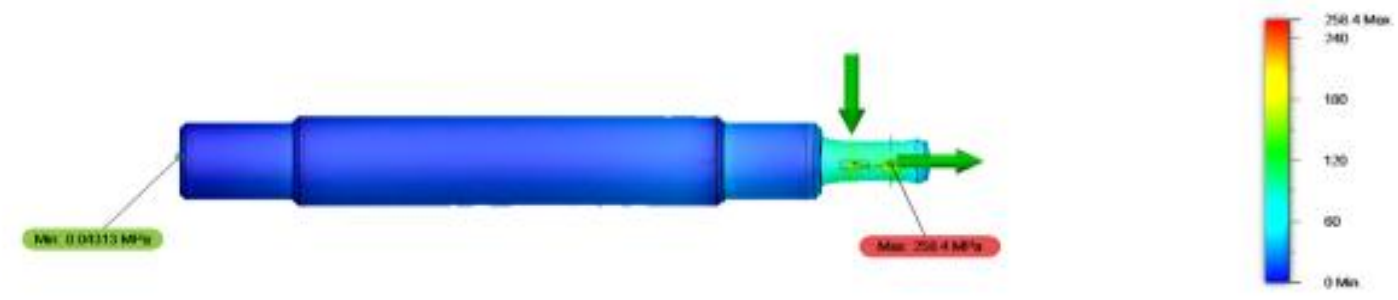

Figure 20. Shaft stress at $70 \mathrm{MPa}$ during operation
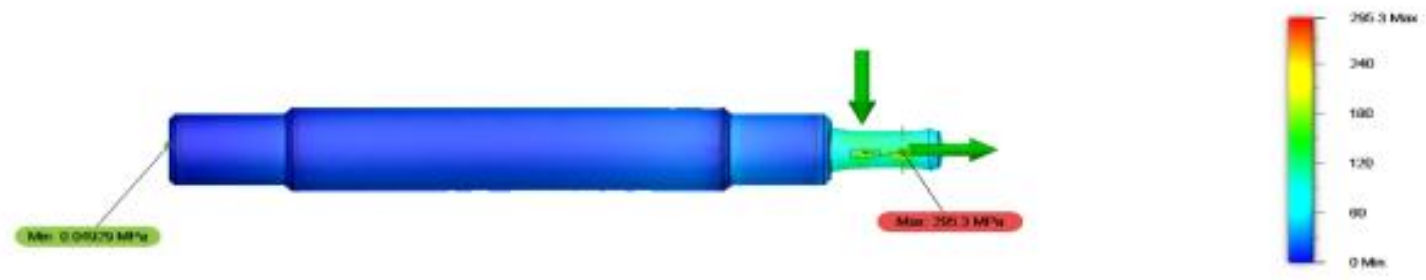

Figure 21. Shaft stress at $80 \mathrm{MPa}$ during operation
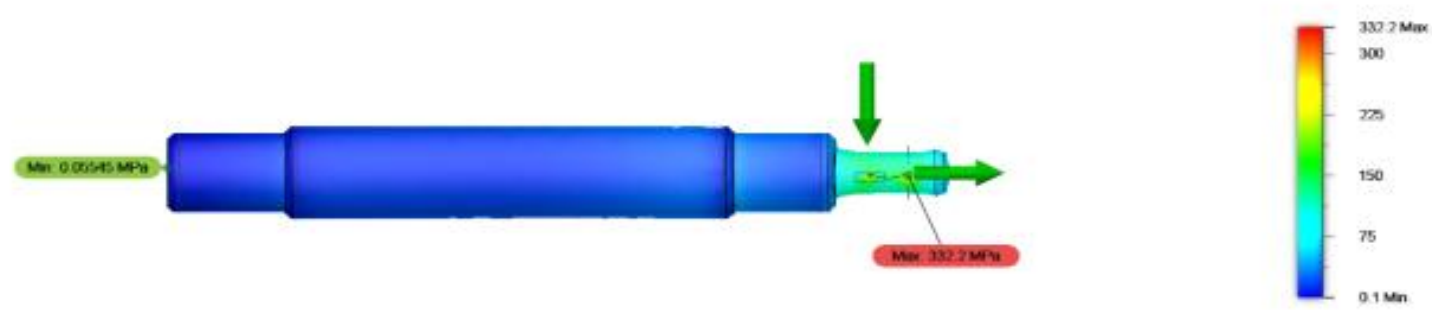

Figure 22. Shaft stress at $90 \mathrm{MPa}$ during operation
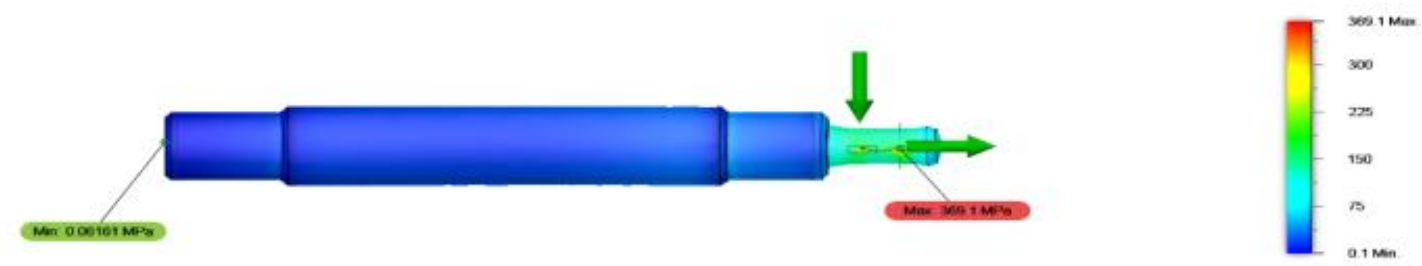

Figure 23. Shaft stress at $100 \mathrm{MPa}$ during operation 
The results in Fig.23 revealed the back pressure at a stress of $100 \mathrm{MPa}$ on the shaft and the results revealed shaft fatigue failure mode of the pump shaft due maximum Von Misses at the keyway slot of 369.1 which is above the ultimate tensile stress $(345 \mathrm{MPa})$. It is observed that the Von Misses stress increases with an increase in back pressure and the keyway slot act as the origin for the pump shaft failure during back pressure. The results in Figure 24 revealed a steady increase of backpressure if the applied stress on the shaft increases

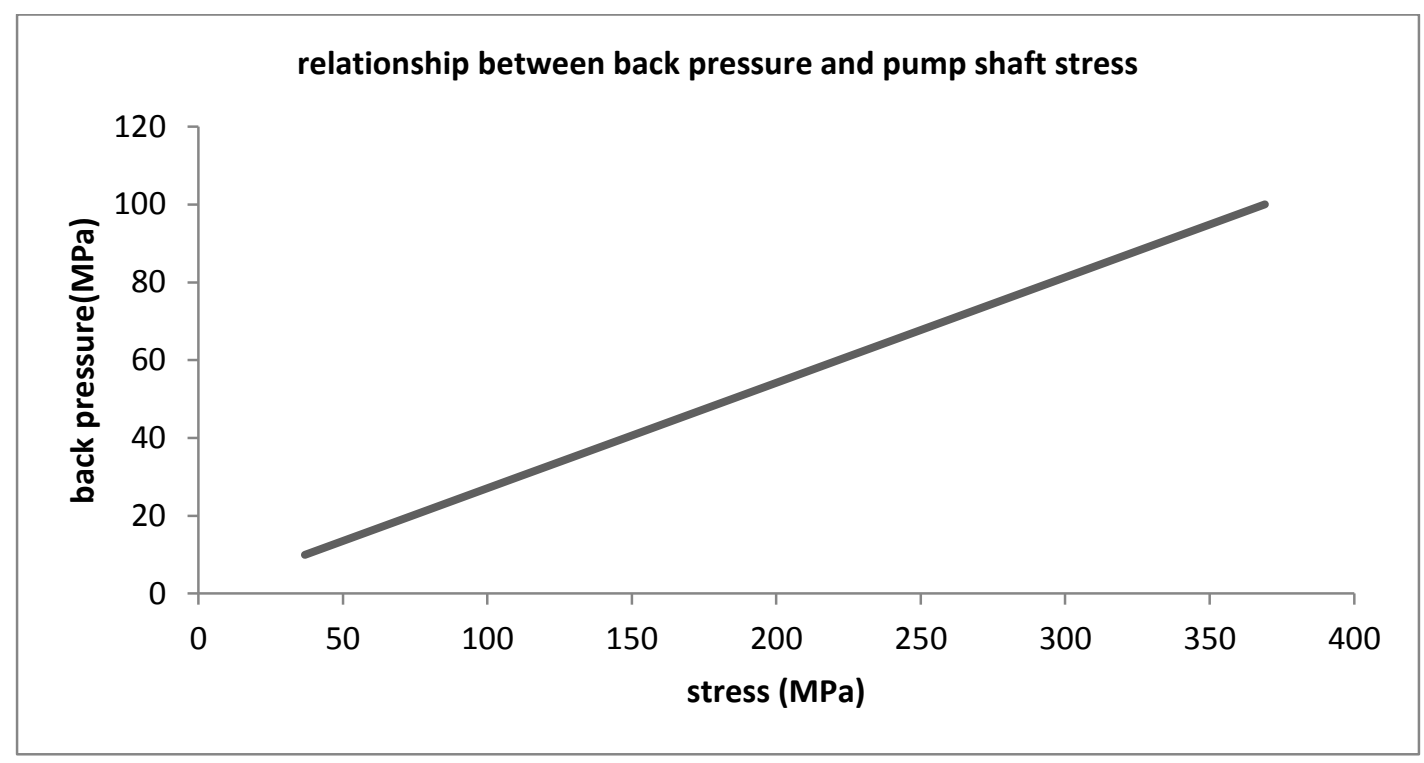

Figure 24. Backpressure against stress on the shaft during operation.

The result revealed in Fig. 24 shown that as backpressure increases the stress in the shaft increases steadily and therefore the system can easily fail if the stress and backpressure are not control during pump operation. In the current study the critical zone was shaft failure usually takes place during backpressure has been revealed and the shaft system can operate effectively without failure if this critical operating zone are respected during shaft operation.

\section{CONCLUSION AND RECOMMENDATION}

The aim of this project is to model and design a centrifugal pump shaft with more enhanced mechanical properties that will withstand backpressure during centrifugal pump operation. To achieve the objective, it was important to theoretically modelled the forces that impacts stress and backpressure during shaft operation. The relevant models were established under defined conditions and the relevant Auto desk fusion 360 software was used to analyze the relationship between back pressure intensity, stress and strain when the shaft is constrained on the drive end bearing and non-drive end bearing using frictionless constrain at extreme back pressure. The following facts were theoretically revealed after modelling the stress-strain relation and performing the relevant simulation using Auto desk fusion 360. The centrifugal pump shaft shows high failure rate at the keyway slot which at increased back pressure. It was also revealed that at extreme back pressure, failure on the centrifugal pump shaft originate from the keyway slot where analysis shows this area as a high concentrated stress zone. Different stress distribution zone where revealed under varying backpressure condition which indicated the different category of shaft failure possibility during backpressure. It was also shown that the stress/strain relationship varying under different backpressure condition and critical elasticity zone were revealed in the study.

\section{REFERENCES}

A.Barmin1, V. B. (2016). Microstructure and mechaMicrostructure and mechanical properties of silicon carbide ceramics reinforced with multi-walled carbon nanotubesnical properties of silicon carbide ceramics reinforced with multi-walled carbon nanotubes. 7.

A. Pineau a, A. B. (2015). Brittle and ductile fracture.

Abdul, P. D. (2019). Failure Theories.

Akin, J. (2009). Concepts of Stress Analysis.

Ali Naeem Odaa, Y. Y. (2017). Numerical Simulation and Life Prediction of Stepped Shaft Under Biaxial Fatigue Loading.

Almasi, A. (2015). How to Optimize Centrifugal Pump Operation.

AZEEZ, A. A. (2013). FATIGUE FAILURE AND TESTING METHODS.

B. Engel, S. S.-M. (2017). Failure Analysis and Fatigue Life Estimation of a Shaft of a Rotary Draw Bending Machine.

Bansal, R. K. (n.d.). Strength of material.

Bhandari, V. (0000). Introduction to Machine Design. 
International Journal of Engineering Research and Technology. ISSN 0974-3154, Volume 13, Number 10 (2020), pp. 2943-2954

○ International Research Publication House. https://dx.doi.org/10.37624/IJERT/13.10.2020.2943-2954

Bhandari., V. (2010). DESIGN FOR COMBINED LOADING \& THEORIES OF FAILURE.

Budris, R. (2016). CENTRIFUGAL PUMP FLOW OPERATING REGIONS AND IMPACT ON RELIABILITY.

D.G. Papageorgiou, K. K. (2018). Fracture analysis of a cooling water pump shaft .

Dimitris G. Papageorgiou, K. A. (2018). Fracture analysis of a cooling water pump shaft.

divedi, h. (2017). MAXIMUM PRINCIPAL STRAIN THEORY.

Dr. B. P. Patel, H. R. (2014). Critical Review on design of shaft with multiple discontinuities and combined,Dutt. B. Thakar.

e, E. n. (2011). transient analysis.

E.R Tomblin, K. B. (2013). CROSS-CONNECTIONS AND BACKFLOW PREVENTION MANUAL.

F. Berndt, A. v. (1999). Pump shaft failures $Đ$ a compendium of case studies.

FAA. (2000). Analysis Techniques.

G.Das, A. S. (1998). Failure analysis of counter shafts of a centrifugal pump.

Gedney, R. (February 1, 2019). Stress-Life Fatigue Testing Basics.

Goran Vukelic 1, *. a. (2016). Predicted Fracture Behavior of Shaft Steels with.

Gulich, J. (2008). centrifugal pumps.

Karney, X. X. (2017). An Overview of Transient Fault Detection.

Kristoffer K. McKee, G. F. (n.d.). A review of major centrifugal pump failure modes with.

KSB. (2018). back pressure speed.

N. Pasca, L. S. (2010). FAILURE ANALYSIS OF A STORAGE PUMP SHAFT.

N.RAJENDAR, .. N. (2017). DESIGN AND ANALYSIS OF COMPOSITE DRIVE SHAFT.

Preven, J. F. (2010). Failure Analysis of Water Pump Shaft.

pvm rao, m. s. (2005). Carbon nanotubes as machine elements. 4.

Richard Leach, . T. (2018). basic of precision engineering.

Rosen, H. (2010). Variability of pump system performance.

Roylance, D. (2001). Introduction to Fracture Mechanics. 2-3.

Roylance, D. (2001). STRESS-STRAIN CURVES.

staff, e. e. (2012). Failure Analysis Of Machine Shafts.

world, w. (2016). RELIABILITY, CENTRIFUGAL PUMP FLOW OPERATING REGIONS AND IMPACT ON.

Wuyi Wan, B. Z. (2018). Investigation on Water Hammer Control of Centrifugal Pumps in Water Supply Pipeline Systems. 